\title{
Caracterização da comunidade San Nícolas del Cerrito, San Ignácio de Velasco, Bolívia
}

A definição de cultura perpassa pelas estruturas de significações socialmente estabelecidas; logo, para sua compreensão, é necessário explorar o campo social. 0 objetivo deste estudo fo investigar os aspectos culturais e etnográficos, a organização social e a política da comunidade San Nícolas del Cerrito, localizada município de San Ignácio de Velasco, no Departamento de Santa Cruz, na Bolívia. Para tanto, foi empregada a a metodologia de observação participante e entrevistas semiestruturadas. Como resultados, destaca-se o surgimento da comunidade, oriunda do processo migratório de famílias que buscaram novas oportunidades e uma vida longe da opressão do Estado A população é composta por mais de trinta famílias, orientadas por uma estrutura herdada das Missões jesuítas do século XVIII. Dentre os atributos culturais, a comunidade ainda mantém tradições autóctones da etnia chiquitana (organização doméstica, a estrutura social, as práticas de cultivos e extrativismo), somada a uma rica diversidade de fauna e flora, influenciadas pela Laguna Marfil e por seus ambientes. Um aspecto de ênfase é a forte relação com a cultura brasileira, pela proximidade com a fronteira e, predominantemente, com a cidade de Vila Bela da Santíssima Trindade, município do estado do Mato Grosso.

Palavras-chave: Espaço Social; Etnografia; Cultura; Costumes Tradicionais.

\section{Characterization of the San Nicolas del Cerrito community, San Ignácio de Velasco, Bolívia}

We understand that the definition of culture consists of structures of socially established significations, for its understanding it is necessary to explore the social field. The objective of the study was to understand the ethnographic cultural aspects, social and political organization of the San Nícolas del Cerrito community, located in the municipality of San Ignacio de Velasco, in the Department of Santa Cruz, Bolivian territory. The methodology of participant observation and semi structured interview is used. As results highlighted the emergence of the community as migration of families in search of new opportunities and freedom; The population composed of more than thirty families, guided by a structure inherited from the Christian Jesuit Missions of the eighteenth century. Among the cultural attributes the community still maintains indigenous traditions of the Chiquitana ethnic group (domestic organization, social structure, cultivation practices and extractivism), adding to a rich diversity of fauna and flora, influenced by Laguna Marfil and its environments. One aspect of emphasis is the strong relationship with Brazilian culture due to its proximity to the border and predominantly with the city of Vila Bela da Santissima Trindade.

Keywords: Social Space; Ethnography; Culture; Traditional Customs.

Topic: Desenvolvimento, Sustentabilidade e Meio Ambiente

Reviewed anonymously in the process of blind peer.
Received: 02/02/2018

Approved: 20/05/2018

Denildo da Silva Costa (iD)

Universidade do Estado do Mato Grosso, Brasil

http://lattes.cnpq.br/8461506995455809

http://orcid.org/0000-0001-7356-5182

denildotupiguarani@hotmail.com

Celia Alves de Souza (iD

Universidade do Estado do Mato Grosso, Brasil

http://lattes.cnpq.br/4260661798494235

http://orcid.org/0000-0002-9068-9328

celiaalvesgeo@globo.com

Solange Kimie Ikeda Castrilon (iD

Universidade do Estado do Mato Grosso, Brasil

http://lattes.cnpq.br/3373034135331436

http://orcid.org/0000-0003-1862-4615

ikedac@gmail.com

Referencing this:

COSTA, D. S.; SOUZA, C. A.; CASTRILON, S. K. I.. Caracterização da comunidade San Nícolas del Cerrito, San Ignácio de Velasco, Bolívia. Revista Ibero-Americana de Ciências Ambientais, v.9, n.1, p.103-118, 2018. DOI: http://doi.org/10.6008/CBPC2179-6858.2018.001.0008 


\section{INTRODUÇÃO}

Cada povo autóctone possui sua história e suas cosmovisões. O povo chiquitano é um grupo étnico sul-americano que se formou a partir de um amálgama de mais de quarenta povos indígenas diferentes, reduzidos e realocados pelas missões jesuíticas (COSTA, 2006). Nas considerações de Silva (2012):

A ação missionária pode ser resumida em dois aspectos principais: a aglomeração de indígenas em reduções (com a consequente e progressiva sedentarização dos grupos) e a imposição de uma língua, o chiquitano com língua geral, também chamada, hoje em dia, de Chiquito pelos linguistas e de Bésiro ou Besoro pelos própios indígenas.

$\mathrm{Na}$ atualidade, os chiquitanos representam um dos trinta e quatro grupos que vivem em áreas urbanas e rurais do departamento de Santa Cruz, na Bolívia (ONU, 2005). São uma das trezentas e cinco etnias do Brasil, habitando os estados de Mato Grosso e de Mato Grosso do Sul (IBGE, 2010).

De acordo com Antas Jr. (2005), as fronteiras políticas não correspondem a espaços culturais consolidados historicamente. Essa afirmação vai ao encontro do que ocorreu com o povo chiquitano: foram divididos geograficamente entre Brasil e Bolívia, condicionados a políticas estruturais de cada nação, que geraram uma configuração descontinuada e separatista. Os grupos organizaram-se e resistiram com suas específicas resiliências e estratégias peculiares.

Ribeiro (1995) a estudou grupos autóctones das águas pretas do rio negro, no Amazonas. São trabalhos que apresentam toda a esfera antropológica de costumes e práticas etnográficas. Estudos de Descola (1998), por exemplo, relacionam a estrutura natural de sentimento nativo com o ambiente e suas práticas, consolidando-se uma relação íntima.

Conforme Ribeiro (1997) são importantes os estudos sobre os conhecimentos desenvolvidos por qualquer sociedade, a relação da natureza com os sentidos de crenças e as adaptações do homem em determinados ambientes. Nas definições de Geertz (1989), o trabalho etnográfico consiste em descrever as configurações superficiais da melhor maneira possivel, reconstruir as estruturas mais profundas e classificálas para chegar a amplas generalizações, partindo de fatos particulares e transpondo profundamente os detalhes para descobrir algo a mais.

Nos âmbitos dos estudos sobre as sociedades, a pesquisa foi embasada na definição da antropologia estrutural de Lévi-Strauss (2012), autor que define essa área como a ciência selvagem que compreende os mitos, a magia, o animismo e outros rituais como recursos de uma história autóctone, desprezados pela ciência racionalista e positiva do século XIX.

No que diz respeito à definição de cultura, Geertz (1989) caracteriza-a como estruturas de significações socialmente estabelecidas, em virtude das quais as pessoas realizam eventos. Por essa razão, a análise cultural consiste em explorar determinado campo social e seu alcance. Uma teoria cultural apresentase sob forma de uma descrição densa, a qual consiste em uma tentativa de compreender, por meio de um esforço intelectual, valores e sentidos de determinados eventos.

Os trabalhos não se limitam a uma descrição superficial das aparências. Descrever uma cultura significa aproximar-se desse elemento de modo que seja possível obter uma explicação a respeito da própria cultura, que, inclusive, definirá o método do investigador. 
A cultura é definida como um sistema de símbolos em virtude dos quais os homens fornecem à vida e compreendem a sua própria existência. Esses sistemas simbólicos orientam os seres humanos como marcos significativos, os quais podem nortear relações reciprocas, conexões com o mundo que os rodeia e o modo como lidam consigo mesmos de maneira mais intensa.

O objetivo deste estudo foi compreender os aspectos culturais etnográficos, além da organização social e política da comunidade de San Nícolas del Cerrito, localizada no município de San Ignácio de Velasco, no Departamento de Santa Cruz, na Bolívia.

\section{METODOLOGIA}

A pesquisa foi realizada na região denominada Terras Baixas, na Comunidade de San Nícolas del Cerrito, no departamento de Santa Cruz, na Província de Velasco, que corresponde ao município de San Ignácio de Velasco (figura 01). Conforme Puhl (2011), sobre a Província de Velasco, a delimitação de toda área cultural a que pertence a província de Velasco é a seguinte: “A Chiquitania ou província de Chiquitos limita ao sul com o Chaco; o rio Paraguai, ao leste, a separa de Mato Grosso; para oeste, se estende até o Rio Grande ou Guapay; e, para o norte, chega aos 15을 graus de latitude oeste" (PUHL, 2011). Sobre a região denominada Chiquitania, Puhl (2011) define-a como:

Nascida a república boliviana, em 1826 foi criada a província de Chiquitos que englobava todas as atuais províncias com populações chiquitanas. Hoje considera-se província de Chiquitos, somente a parte sul da Chiquitania, situada nas proximidades da ferrovia Corumbá-Santa Cruz, composta pelos territórios das ex-reduções de San José, San Juan Bautista e Santiago e seus entornos. Assim, quando na Bolívia se fala agora em província de Chiquitos, a referência é só a San José e arredores. Por esta razão quando nos referimos a população como chiquitos consideramos o período colonial e republicano quando toda Chiquitania era uma só província e quando falamos em chiquitanos consideramos toda a população das províncias com descendentes desta etnia na atualidade.

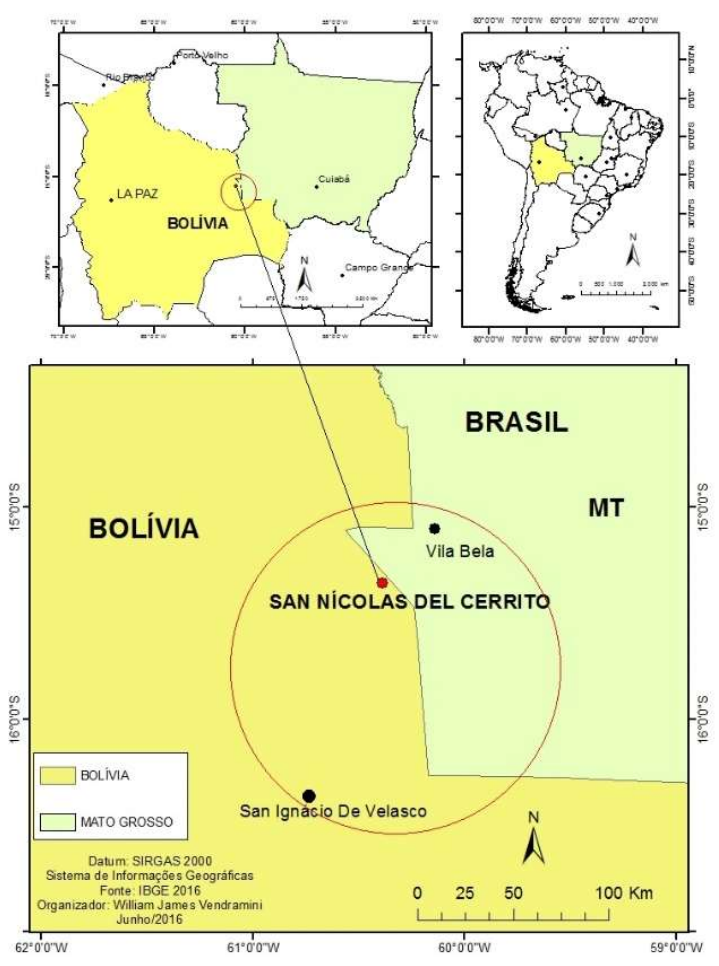

Figura 01 - Localização da comunidade pesquisada 
Nesta etapa do trabalho, foram a fase dos trabalhos foram realizados estudos de gabinete e pesquisas trabalho de campo (MALINOWSKI, 1978). Fontes bibliográficas foram utilizadas como com fontes bibliográficas como recurso de informação e ferramenta de busca para compreender o universo local pesquisado (BERNARD, 2006). Trabalhos acadêmicos e acervos, publicações nacionais e internacionais, relacionadas à temática etnográfica também foram empregados como fonte de consulta para assim, procedemos com leituras e escritas. a nível nacional e internacional.

O pesquisador deslocou-se até onde ocorreu deslocamento pesquisador até a cidade de San Ignácio de Velasco (Casa de Cultura) e de Santa Cruz de la Sierra (museu e biblioteca etnográfico antropológico e Centro de investigaciones históricas y antropológicas), tendo acesso à assim se tornando acessível um acervo para organizar banco de dados e para desenvolver este trabalho. Para fomentar este trabalho, foram feitos trabalhos de estudos com extensos levantamentos bibliográficos ao mesmo tempo em que houve o convívio vemos contiguamente a convivência contígua a com comunidade para compreender melhor o espaço de San Nícolas del Cerrito.

Foram utilizadas publicações nacionais e internacionais a nível nacional e internacional. O pesquisador deslocou-se até onde ocorreu deslocamento pesquisador até a cidade de San Ignácio de Velasco (casa de cultura) e de Santa Cruz de la Sierra (museu e biblioteca etnográfico antropológico e Centro de investigaciones históricas y antropológicas), tendo acesso a assim se tornando acessível um acervo para organizar banco de dados e para desenvolver nosso trabalho.

A partir de entrevistas semiestruturadas com cinco informantes o estudo foi realizado junto da comunidade com cinco informantes (BERNARD, 2006). Compreendemos a Em virtude da natureza social e cultural da comunidade, Com as visitas e convivência a comunidade San Nícolas del Cerrito, realizamos trabalho de a escolha pautou-se na observação direta (GEERTZ, 1989) e na observação participante (WHYTE, 2005), com inserção total no cotidiano local e na metodologia antropológica de olhar, ouvir e escrever (OLIVEIRA, 2006), a fim de coletar Assim, coletamos dados para escrever com mais autoridade sobre essa comunidade. sobre os aspectos deste capítulo. As imagens fotográficas (KOSSOY, 1998) foram uma estratégia que melhor auxilia aclararam o entendimento e validaram o testemunho do momento no tempo e espaço (BARBOSA et al., 2016), compondo o método narrativo e etnográfico.

Como método narrativo e etnográfico, utilizamos imagens fotográficas (KOSSOY, 1998), uma estratégia que melhor auxilia no entendimento e testemunho do momento no tempo e espaço (BARBOSA et al., 2016).

\section{RESULTADOS E DISCUSSÃO}

A comunidade de San Nícolas del Cerrito possui uma rica diversidade de ambientes vegetais, influenciados pela Baía Marfil e por seus afluentes. Sobre a Bolívia, Silva (2012) informa que se trata de um $\Theta$ território é-dividido em duas partes distintas: região andina (alta, fria, árida e rica em minérios) e região das terras baixas (formada por ricas planícies, com clima tropical, rica em petróleo e gás natural). A 
comunidade de San Nícolas del Cerrito está localizada na região das terras baixas. Assim, definindo as terras baixas, Birk (2000), (apud SILVA, 2012), escreve:

As "terras baixas" cobrem toda a parte norte e leste da Bolívia e dividem-se em quatro regiões: Yungas, Amazônia, Chaco e Chiquitania. Yungas formam uma zona de transição entre as montanhas e cordilheiras dos Andes e a Amazônia, ao norte do país. A Amazônia, por sua vez, é formada por grandes extensões de florestas úmidas, apresentando alta diversidade de espécies de plantas. Na parte sul desta região encontram-se amplas planícies cobertas de variedades vegetais que são aproveitadas como pastos por grandes rebanhos de gado bovino. O Chaco é uma região de intenso calor, coberta por matas baixas, savanas áridas e algumas áreas úmidas. A Chiquitania, no noroeste do país (Departamento de Santa Cruz), é uma região menos úmida e está coberta por uma paisagem em que se alternam bosques semi-úmidos e savanas. O conjunto das "terras baixas" possui uma cobertura vegetal de $445.000 \mathrm{~km}^{2}$ sobre uma extensão total de aproximadamente $763.000 \mathrm{~km}^{2}$. (SILVA, 2012).

A denominação foi dada porque a região possui altitude menor em comparação com outras áreas do país, possuindo grandes planícies periodicamente inundáveis por recursos hídricos de cada região e bacia. Conforme Salazar (2010), em San Nícolas del Cerrito, 60\% da área sofre inundação sazonalmente, nos períodos das enchentes e chuvas na região.

\section{A organização cultural e social da comunidade San Nícolas del Cerrito}

San Nicolas del Cerrito é uma comunidade localizada a dois quilômetros de distância do território brasileiro (figura 02). Sem acesso à água encanada e luz elétrica, existem geradores a base de combustível que são acionados em ocasiões especiais, porém nem todas as casas dispõem dessa tecnologia.

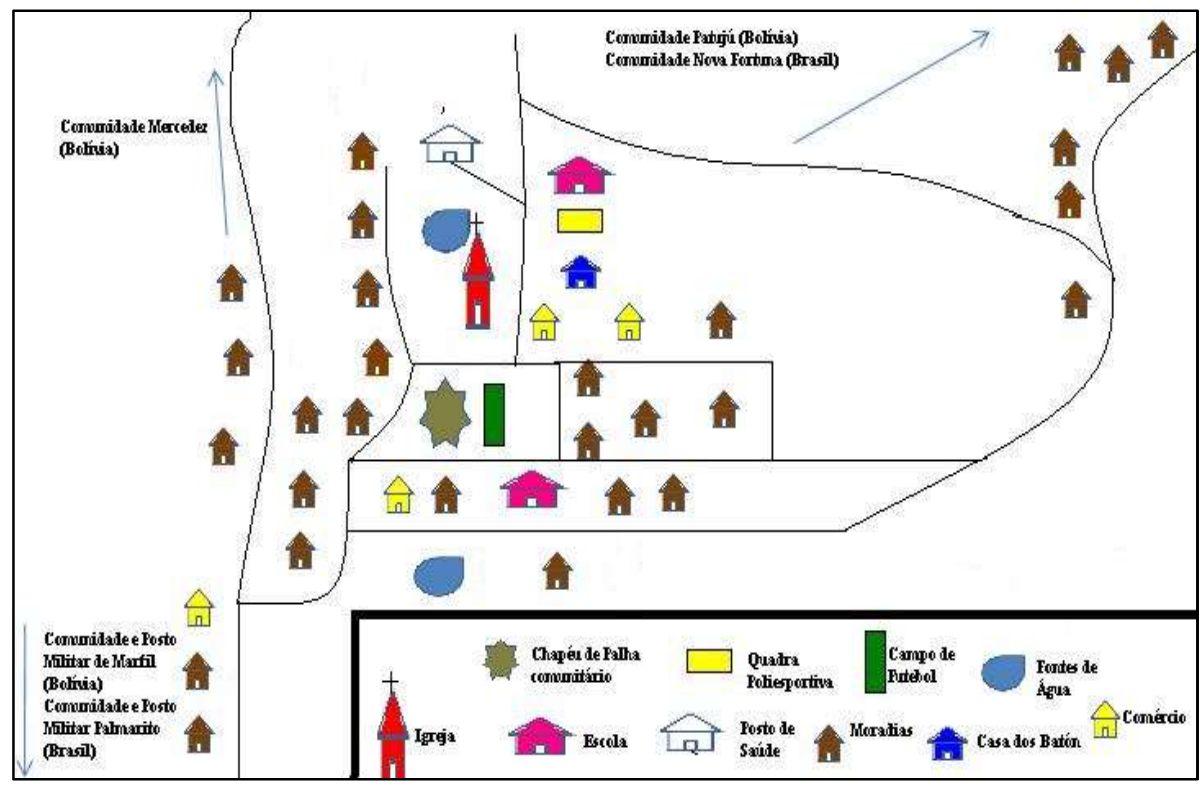

Figura 02 - Esquema organização estrutural da Comunidade.

Para Santos (2006), a idade histórica de uma localidade é a data em que, na história concreta, a tecnologia incorpora-se à vida de uma sociedade. Para o autor, é o lugar que atribui às técnicas o princípio de realidade histórica, relativizando o seu uso, integrando-as em um conjunto e em uma vida, retirando-as de sua abstração empírica e atribuindo-Ihes efetividade histórica. 
Conforme relatos, a comunidade em questão surgiu na década de 1970, quando cinco famílias migraram de uma localidade chamada Marfil, após a inauguração do destacamento militar boliviano, na fronteira com o Brasil. A migração teve como justificativa a severa restrição à liberdade imposta pelos militares. São faladas três línguas na comunidade: espanhol (com maior frequência e domínio), $\Theta$ português (com grande incidência pela fronteira com o Brasil) e o bésiro (língua indígena materna, pouco utilizada).

O sistema e a organização do espaço habitado, da mesma forma que outras comunidades chiquitanas, mantêm o padrão missionário: a igreja no centro da povoação, pois é o monumento mais importante e o patrimônio mais zelado. Tudo gira em torno da igreja, a festa mais importante é a do santo padroeiro, San Nicolas, ocorrendo dia 06 de dezembro.

As famílias estabeleceram-se no espaço da atual comunidade criando roças. Aos poucos foram chegando mais pessoas. Batizaram a nova comunidade em homenagem ao santo padroeiro, pois uma família possuía uma imagem pequena de San Nicolas (em português, São Nicolau). O nome Cerrito (em português: pequena serra ou montanha) foi dado por conta da existência de uma formação montanhosa pequena em meio ao campo cerrado. Segundo relatos populares, foi algo que surpreendeu os primeiros moradores.

A área pertencia à congregação cristã católica de San Ignácio de Velasco e foi doada pela Igreja à população local. Teve sua demarcação e titulação realizada pelos órgãos nacionais na data de 11 de janeiro de 2010. Atualmente, representa uma área de 2543,312 hectares.

A comunidade não se distingue como indígena, mas como campesina. Possui uma estrutura interna de organização política semelhante às implantadas pelos jesuítas nas missões. Lá existe uma casa designada Casa de los Bastões, onde ficam todos os instrumentos administrativos; é um espaço de reuniões. A diretoria que coordena a comunidade é denominada cabildo, tradicionalmente é formada por doze membros.

Na comunidade San Nícolas del Cerrito, o cabildo é organizado por seis membros: primeiro cacique geral; segundo cacique (autoridade máxima da comunidade); um secretário (responsável pela escrita e documentações); um tesoureiro (encarregado de organizar o setor financeiro); e dois bocais (mensageiros de reuniões, de eventos e responsáveis por outros recados).

O cacique, que, em San Nícolas, atualmente é uma mulher, é responsável por representar a comunidade perante as autoridades em outros locais (políticos, militares e outros segmentos). Cada mandado de cacicado dura, em média, um ano, podendo ser renovado. O cacique é escolhido por meio de uma assembleia popular na comunidade.

O cabildo tem autonomia para resolver questões internas por meio de regras e de punições. Conforme a gravidade dos atos cometidos, o habitante pode ser condenado a chicotadas que, de acordo com o julgamento, podem variar de seis a vinte e quatro repetições. O morador também pode pagar multa em dinheiro ou prestar serviços comunitários. Além do cabildo, existem grupos denominados juntas, que organizam as questões educacionais e religiosas.

Raras são as interferências políticas em San Ignácio de Velasco; ocorrem somente quando são solicitadas ou por conta de denúncias. No ano de 2016, a comunidade foi multada pelas autoridades do 
governo em vinte sete mil dólares, devido ao fato de estar envolvida com alguns incêndios na região e com a venda ilegal de madeira para brasileiros.

O não pagamento da multa acarreta o risco de perderem o território para o governo. Os moradores da comunidade decidiram, em assembleia local, explorar e vender madeiras nobres da reserva comunitária, ação que passou a ser assistida pelas autoridades e de acordo com as leis nacionais. Além das árvores, a comunidade possui um rebanho bovino coletivo com aproximadamente trinta animais.

Em toda sua estrutura, a sociedade é composta por trinta e duas famílias, uma escola, um posto de saúde com médico residente, uma igreja matriz católica e dois comércios de diversos gêneros (figura 02).

Um ônibus particular (figura 04) funciona como veículo de transporte da comunidade, realizando um transporte por ônibus particular que faz um trajeto até a sede da província, a cidade de San Ignácio de Velasco, todos os domingos e terças-feiras. O ônibus faz o trajeto pela Chiquitania, de San Ignácio até a Comunidade de Patujú, a $5 \mathrm{~km}$ após San Nicolas del Cerrito, retornando no e retorna o dia seguinte. Cada viagem dura em média sete horas, em um trajeto de $170 \mathrm{~km}$ de estrada sem pavimento asfáltico.

A comunidade é desprovida de grandes comércios, as empresas são ganaderas (pecuária), as fontes de renda que a permeiam são trabalhos em estâncias bolivianas ou fazendas brasileiras. Durante a semana, realizam uma espécie de migração dos homens da comunidade, os quais regressam apenas nos finais de semana ou em dias festivos.

Em alguns casos, o cultivo e o extrativismo ficam restritos às mulheres, aos homens sem emprego e aos idosos. Em geral, todas as famílias têm seu espaço de roça (chaco), com média de um hectare, feito em forma de coivara (roça derrubada com machado e queimada, com muitos tocos e troncos de árvores ao meio a cultivo) como sistema agroflorestal (figura 08).

Nesse espaço de cultivo, a identidade étnica abrolha com práticas culturais, produz-se farinha de mandioca (Manihot esculenta), pratica-se o extrativismo vegetal e animal nos bosques, planta-se o suficiente para a subsistência. Os produtos que sobram, os excedentes, são comercializados e/ou trocados por outros dentro da própria comunidade ou em outras, quando são realizadas visitas festivas ou familiares. Com a saída dos homens, as mulheres assumem os cuidados da roça e das criações.

Como não existe comércio de carnes, a caça e a pesca são importantes atividades praticadas por todas as famílias (figura 03). A caça é muito praticada, principalmente no período seca. Nesses casos, os caçadores posicionam-se próximos aos poucos mananciais de água e esperam que os animais apareçam. A pesca também é facilitada no período de seca, em lagoas temporárias que estão secando ou na Laguna Marfil.

Em relação aos animais, existe uma maior preferência por mamíferos e aves. Quanto aos peixes, os que possuem escamas são os favoritos. Como não possuem resfriadores para armazenar carne, os habitantes consomem o alimento no ato da caça/pesca e secam o excedente para consumo posterior. Geralmente, as caças ou pescas são organizadas coletivamente por várias pessoas e com auxílio de cães para orientarem as investidas. Conforme os períodos do ano, os moradores conhecem as frutas em maturação, onde estão os animais e quais as melhores estratégias. 
Vale destacar que caças e pescas são orientadas pelos ciclos cosmológicos, datas religiosas e ciclos biológicos das espécies. Não se matam animais com filhotes ou os que estão em fase de reprodução, bem como não se pratica a pesca fora do período de reprodução dos peixes. Uma prática muito comum, após a caça ou pesca, é a de compartilhar produtos com as pessoas mais próximas. Mauss (2003) descreve esse fato como um fenômeno social denominado de dádiva.

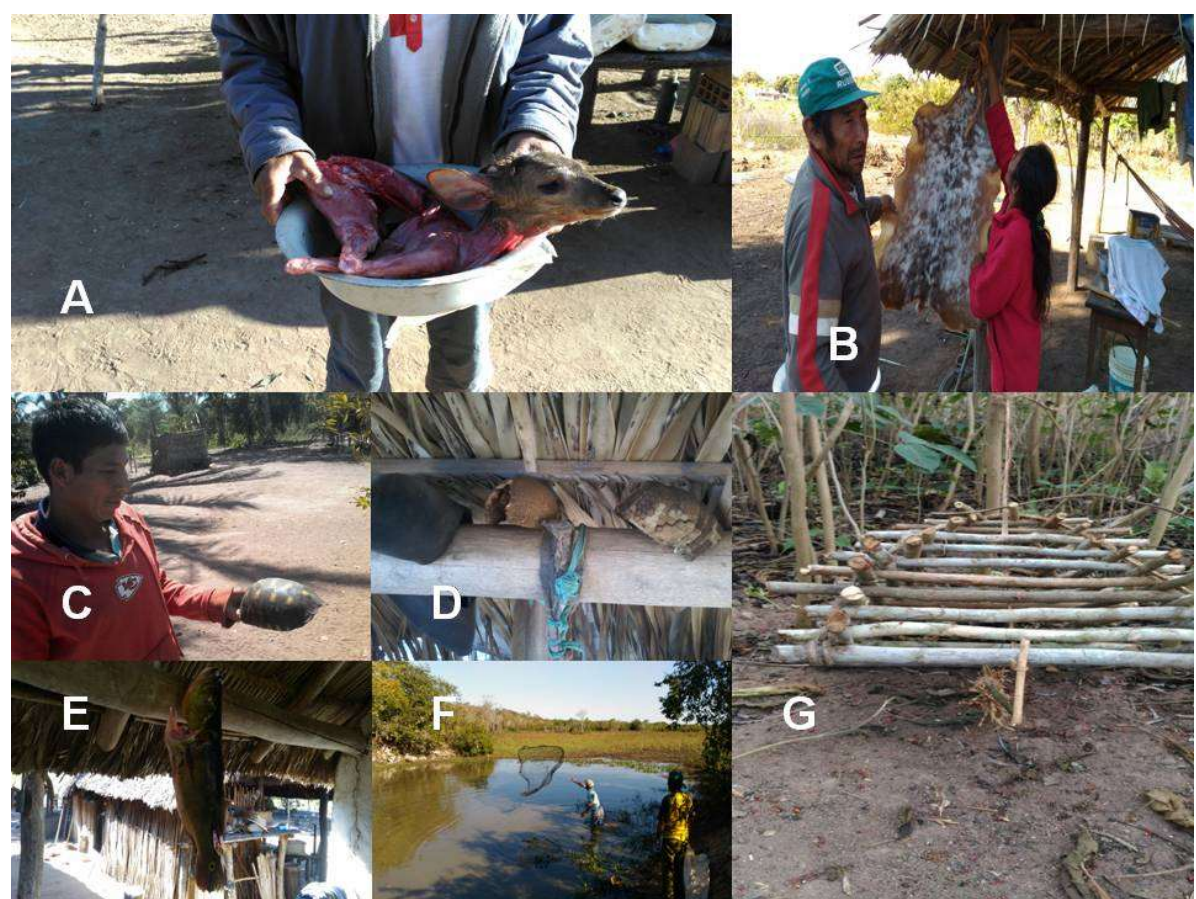

Figura 03 - Caça, pesca e armadilha: A) Veado catingueiro (Mazana gouazoubira), B) Couro do veado campeiro (Ozotoceros bezoarticus), C) Jabuti (Chelonoidis carbonária), D) Tatu-bola (Tolypeutes matacus) e tatu-galinha (Dasypus novemcinctus), E) Tucunaré (Cichlia sp.), F) Pesca com tarrafa e G) Armadilha para prender aves - arapuca

Os moradores que trabalham em fazenda, às vezes, levam carne bovina aos seus familiares que ficaram na comunidade, mas é algo raro. Em geral, os habitantes criam animais para o consumo. Galinhas, patos, porcos e perus são confinados nos espaços domésticos (quintal), sempre com total zelo e cuidado. Os produtos da roça auxiliam na criação desses animais, os quais, geralmente, são consumidos em ocasiões especiais, como dias festivos, por exemplo.

Uma prática muito comum na comunidade é o sistema de xenimbabos (criação de animais silvestres como domésticos). Existe uma maior preferência por aves (figura 04). Erikson (2012) define que os xenimbabos são práticas autóctones muito peculiares da cultura, onde os animais silvestres são membros familiares. $\mathrm{O}$ autor relaciona essa prática ao simbolismo complexo a relação simbólica complexa que qual os ameríndios estabelecem entre os lugares dos quais se apropriam que se apropriaram (seu habitat) e aos seres vivos que ali se encontram e transitam.

A roça chiquitana é constituída de práticas etnoecológicas com apropriação da natureza. Toledo (2001) define três elementos de suas práticas: kosmos (sistemas de crenças), corpus (sistemas cognitivos) e práxis (conjunto de práticas); ou seja, conhecimento ambiental, parte integrante de sua identidade cultural. Os cultivos são fontes de alimentação familiar e comunitária, sem finalidades comerciais (figura 05). 


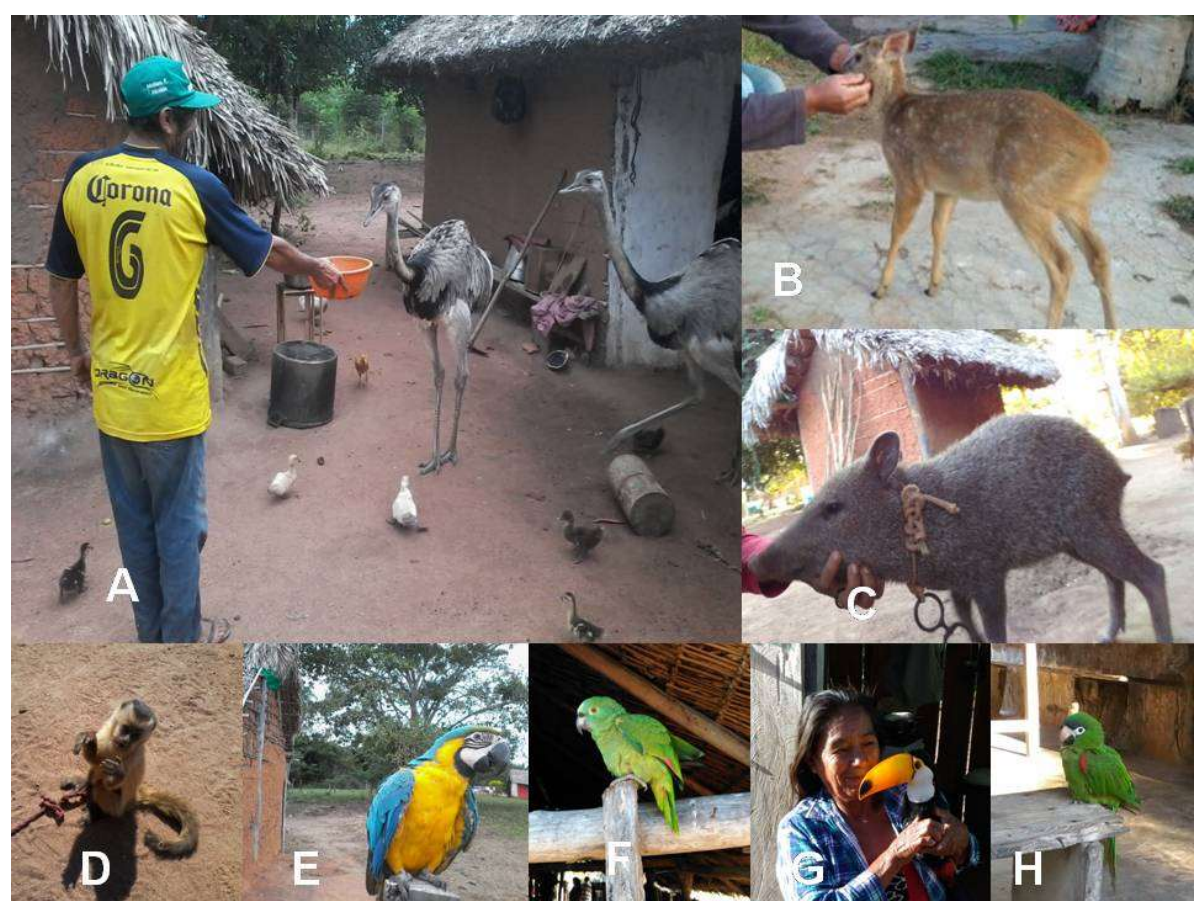

Figura 04 - Xenibabos: A) Ema (Rhea americana), B) Veado mateiro (Mazana americana), C) Queixada (Tayassu pecari), D) Macaco-prego (Sapajus apela), E) Arara canindé (Ara ararauna), F) Papagaio (Amazonas aestiva), G) Tucanuçu (Ramphastos toco) e H) Maracanã-pequena (Diopsittaca no bilís).

Schuwarz (1995) menciona o conhecimento dos chiquitanos, os quais classificam os solos pela qualidade e compatibilidade de cultivos: terra preta (Cubusicurr) para cultivo de amendoim; terra vermelha (Taturicurr) para arroz, milho, cana e banana; e terra arenosa (Cuososa) para mandioca e batata.

A atividade é denominada chaco de palo quemado, devido aos tocos e troncos queimados no meio do roçado. O manejo da floresta para consolidar uma roça é realizado por etapas durante o ano. Com o encerramento do período das chuvas e a efetivação da estiagem, em junho e julho, inicia-se o roçado de arbustos e herbáceas (uma semana em média). Depois, derrubam-se algumas árvores (três semanas em média) e secam-nas (dois meses), realizando a queima controlada em setembro (figura 05).

Após a queima, o correto é esperar pelas primeiras chuvas, que geralmente acontecem em outubro. Só depois se inicia o processo de semeadura dos cultivos, que são norteados pelas fases da lua, crescente ou cheia. Com a semeadura, em outubro, os cultivares (milho, mandioca, banana, tabaco e batata) absorvem todas as chuvas de dezembro, janeiro, fevereiro e março até colheita.

Durante período de colheita, são realizadas práticas mágicas, benzimentos ritualísticos com ervas e outros produtos de origem animal para proteção e prevenção de ataques de animais silvestres, como caititus (Pecari tajacu), cutias (Dasyprocta aguti) e queixadas (Tayassu pecari).

Com o encerramento das colheitas, ocorre o sistema de rotação nas roças. Permanece a sucessão ecológica de plantas nativas, aguardando a nova estiagem e o preparo para novo ciclo de plantações. Essas sucessões, juntamente com os fragmentos da produção passada, servem como biomassa e matéria orgânica ao solo para novos cultivos.

O quintal das moradias é um espaço de cultivo cultural adaptado à flora local, preservando-se algumas espécies nativas e exóticas de plantas. Para os chiquitanos, existe uma classificação entre os vegetais cultiváveis (plantados) e os selvagens (naturais). Os quintais são mantidos sempre bem limpos (figura 06). Há 
uma demarcação, limites em todos os quintais, separando os espaços humanizados e naturais. As cercas evitam a entrada de grandes animais como bovinos e equinos, os quais são criados soltos na comunidade.
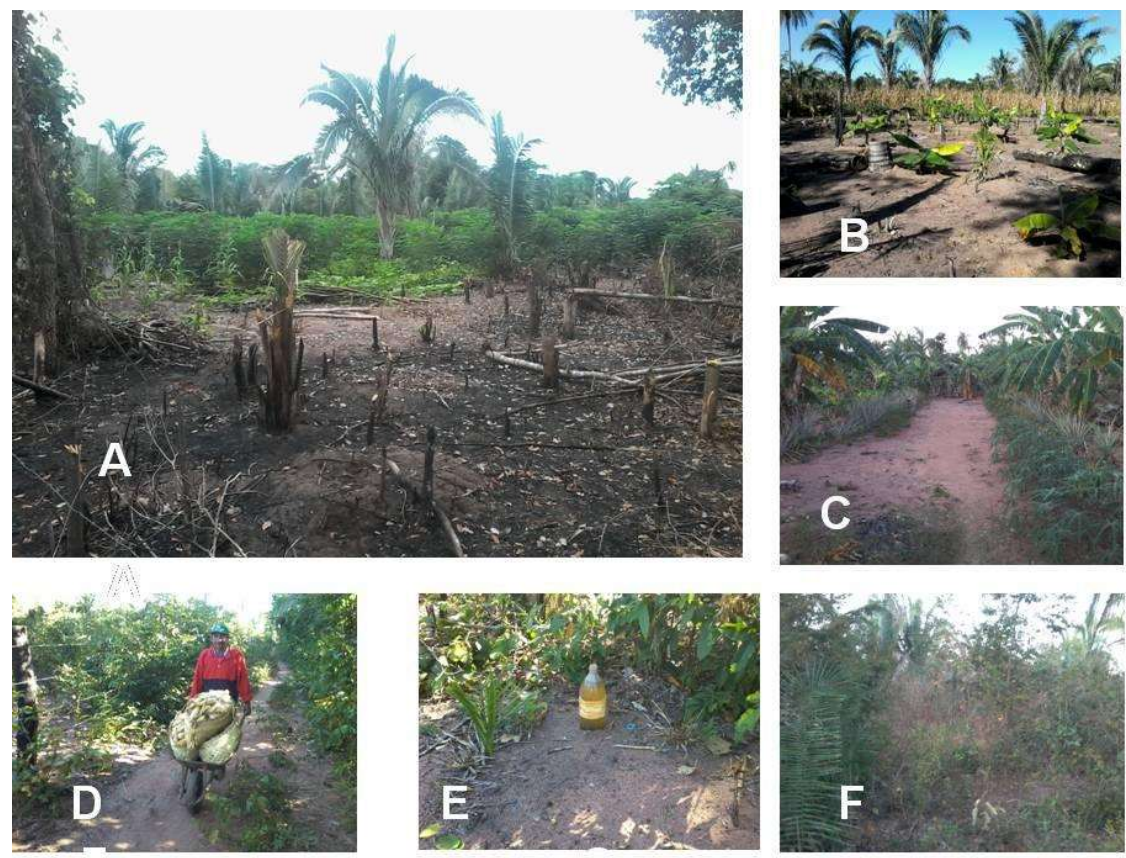

Figura 05 - Roça A, B e C) Roça Palo Quemado: com cultivos diversificados, com manejo agroflorestal, D) Colheita milho seco, E) Benzimento e proteção para evitar ataques animais silvestres nas roças e F) Roça abandonada para sucessão ecológica e fertilidade do solo

As moradias são construídas dentro de uma área familiar, são determinadas pelo patriarca. Os filhos oriundos dos matrimônios constroem suas moradias e passam a residir próximos aos pais. Geralmente, os espaços são divididos por famílias que se organizam de acordo com as gerações.

Os cômodos são bem separados e definidos: punilla ou sala de reunião (sem paredes em forma de área) é onde se recepcionam as visitas e todos se reúnem para conversar; dormitorio ou quartos de dormir (separados dos outros cômodos e divididos por gênero e idade); cocina ou cozinha (separada e fora dos outros cômodos) é local onde preparam as refeições, consumem-se os alimentos, estocam-se mantimentos alimentícios e medicamentos, também é o lugar de repouso para animais domésticos e xenimbabos; perchele é uma espécie de paiol onde são guardados todos os objetos e parte das produções; luchas são banheiros para banho; e outro espaço, as letrinas são sanitários para defecar (geralmente mais afastados de todos os outros cômodos, ao final da área humanizada próximo ao bosque). Também existem locais para lavar os vasilhames e roupas, geralmente perto da cozinha (figura 06).

Ao adentrar em uma cozinha chiquitana, imergimos em um universo cosmológico de saberes; tudo relacionado à alimentação ou a medicamentos está ali. Produtos de origem animal ou vegetal são armazenados para serem utilizados de acordo com as necessidades. Parte dos alimentos coletados nas colheitas é armazenada e preservada pela quantidade de fumaça e calor.

O fogão a lenha possui, geralmente, uma localização central. A todo momento é alimentado com brasas para ser utilizado. A cozinha e o quintal são espaços exclusivos de gestão feminina, bem como o cultivo de ervas medicinais e aromáticas. As famílias geralmente são compostas por muitos integrantes. $\mathrm{O}$ apellido 
(sobrenome) é indicativo de referência. Como é de hábito em estrutura patriarcal, o sexo masculino é que determina as tomadas de decisões.

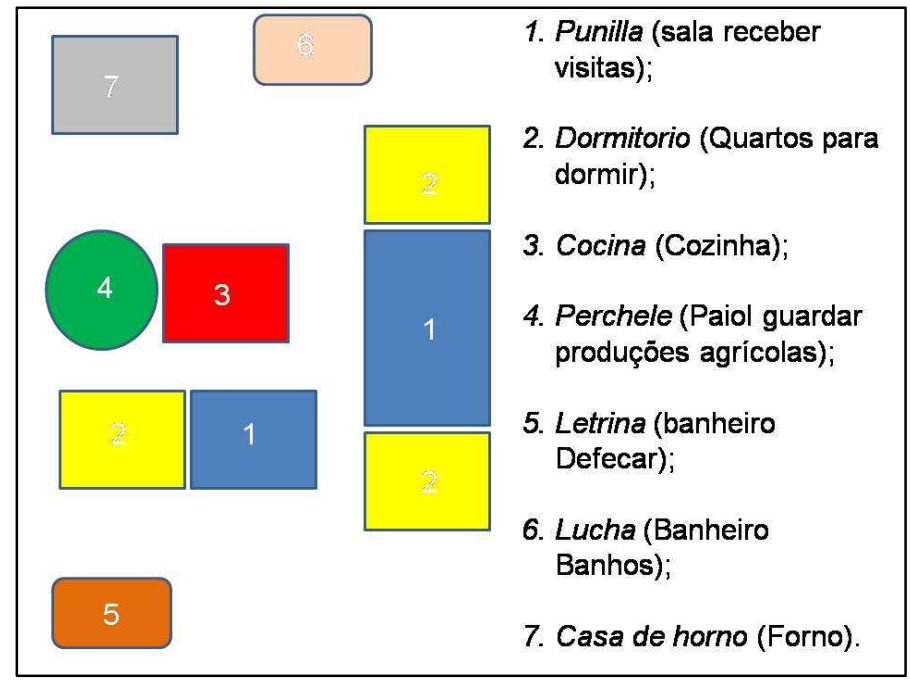

Figura 06 - Estrutura doméstica de uma moradia chiquitana.

Existem algumas instalações que são de uso comum pela comunidade: posto de saúde; $\ominus$ espaço para manifestação política por plebiscito; poço artesiano comunitário, de onde todos retiram água salobra para diversos fins; motor gerador de eletricidade movido a combustível.

Sobre as práticas sociais, podemos considerar que o milho (Zea mays) é base alimentar da comunidade, sendo cultivadas três espécies crioulas. É tradição recepcionar visitantes com a bebida chicha, fabricada a partir de mandioca ou milho. Existem relatos de que, em tempos anteriores, produziam-na a partir de bocaiuva totaí (Acrocomia aculeata (Jacq.) Lodd. ex Martius). $\mathrm{O}$ ato de mascar folha de coca (Erythroxylum coca) com bicarbonato de sódio, denominado popularmente fazer bolo, é uma prática comum entre os homens. Fazer o tamal (pamonha de milho seco moído) e a fiagem do algodão para confeccionar linhas e posterior chipa (rede de pesca) e halmaca (rede de dormir) também são práticas frequentes e tradicionais.

As refeições são servidas sem tempero (sal ou açúcar), que ficam disponíveis na hora de consumir os alimentos onde fica a escolha na hora de consumir é muito comum manter fogueira acesa para aquecer-se e dialogar nas madrugadas mais frias do ano. O pilão é um integrante dos cenários domésticos da cozinha, utilizado para preparo de muitos alimentos. Tradicionalmente, no período da noite, as cadeiras e outros assentos permanecem virados ao contrário para não dar aposento aos espíritos que vagam pela escuridão. Mesmo com sendo o catolicismo a religião predominante, as crenças espirituais dos bosques, os fenômenos e os presságios são parte integrante da vida dos chiquitanos (Figura 07).

O espaço doméstico abriga um conjunto de materiais de origem animal e vegetal, demonstrando manejo ao ecossistema local. Uma estratégia ecológica de bem-estar humano para suprir necessidades básicas humanas.

Sobre a educação escolar formal, a comunidade dispõe da Unidad Educativa Simón Bolivar, que surgiu na década de 1980 com uma estrutura simples, mas hoje está em sua terceira construção física, de 
material trazido de San Ignacio de Velasco. A escola possui três salas de aula (funcionando) e um banheiro masculino e feminino (sem funcionamento), não possui energia elétrica nem água encanada. Os alunos e professores, quando necessitam, fazem suas necessidades básicas no bosque.
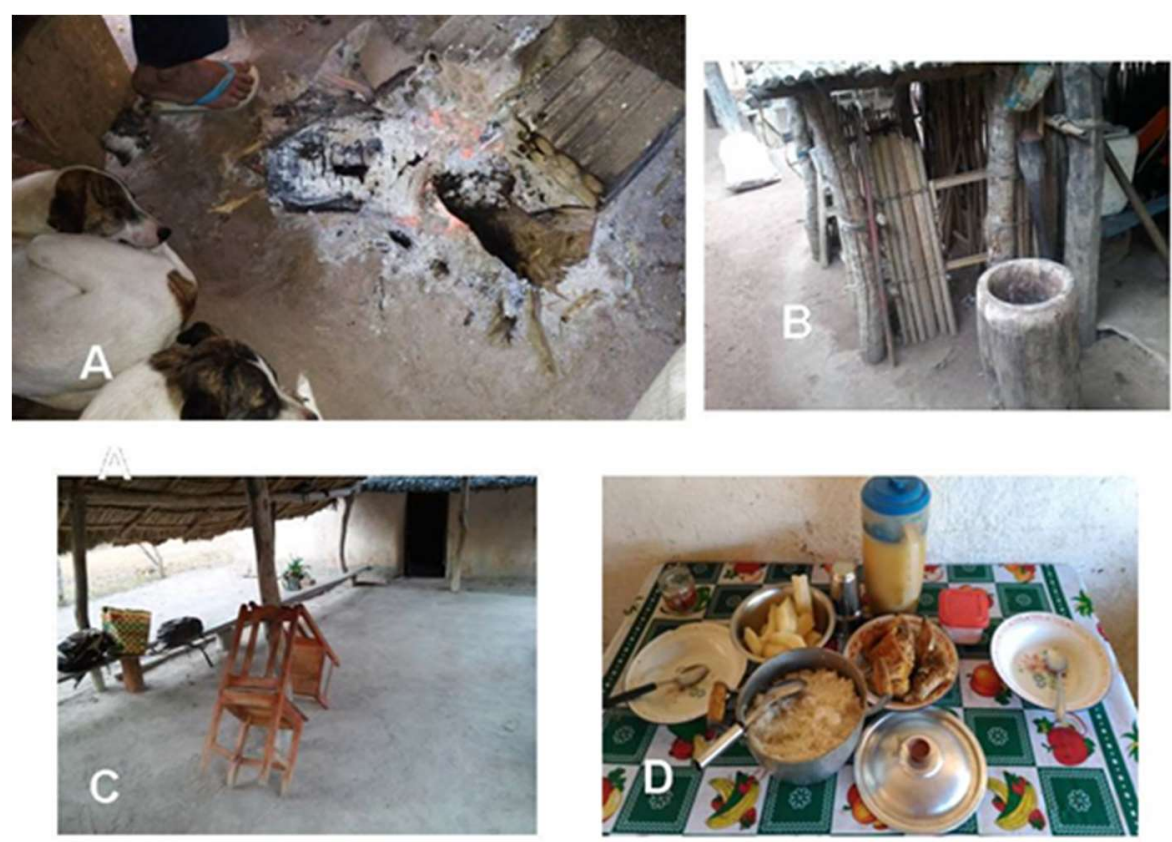

Figura 07 - Costumes II: A) primeiros momentos da manhã se aquecer junto à fogueira, B) Espaço doméstico com pilão, C) As cadeiras e bancos sempre virados para não ser usada por espíritos do mal durante noite, D) Refeição típica

a base de arroz, mandioca cozida sem sal, carne (na foto pescado) e Chica (bebida feita de milho ou mandioca fermentada).

Como a escola da comunidade não tem o ensino secundário (equivalente ao ensino médio brasileiro), os estudantes, logo que terminam o primário (ensino fundamental), vão trabalhar nas fazendas e, em seguida, casam-se. As famílias que detêm recursos mandam os filhos para cidades bolivianas de San Ignácio de Velasco ou de Santa Cruz de la Sierra, para que eles possam dar continuidade aos estudos, trabalhar e até ingressar na universidade. Alguns, que possuem familiares no Brasil, também optam por vir estudar nas escolas brasileiras e buscar trabalho em nosso país. Dificilmente os que migram voltam para morar na comunidade, só retornam nos períodos de férias ou festivos. Assim, a comunidade em sua maioria é formada por crianças, os jovens são poucos.

O refeitório está instalado em um espaço fora da escola, na comunidade, um local coberto de palha, onde as refeições são preparadas por uma mãe da comunidade que assume a função semanal por escalas. $O$ fogão é a lenha, os produtos alimentícios e as lenhas são arrecadados na comunidade entre os moradores que contribuem, pois a alcadia de San Ignácio envia poucos recursos. Geralmente faltam muitos gêneros alimentícios. A comunidade possui um rebanho bovino numeroso, mas esse recurso é utilizado para festa comunitária religiosa.

São três professores que possuem vínculo com a administração de San Ignácio de Velasco. Em 2016, estudaram 35 alunos no sistema primário. Funcionando somente no período matutino, as aulas iniciam às 8 horas e encerram às 12 horas. Quando entram, os alunos tomam leite. Há um intervalo de 15 min às 10 horas. 
Quando saem, os alunos passam no refeitório para almoçar, refeição que, na maioria das vezes, é arroz, feijão e mandioca.

Como a alcadia (prefeitura) não paga merendeira e nem oferta serviços administrativos, cabe aos moradores da comunidade, aos professores e aos alunos organizarem um mutirão de serviços para limpar a escola, carpir o pátio e zelar pelo patrimônio.

A escola possui uma quadra esportiva de concreto, construída recentemente, mas não dispõe de materiais como bolas de futebol, basquete e vôlei. Os estudantes usam uma bola de borracha simples ou improvisam uma bola feita de sacola plástica. Um dos problemas apontados por moradores, pelos professores e pela cacique é a falta de professores na região. Muitos jovens vão à cidade para estudar e trabalhar. Segundo a cacique, ano de 2015, doze alunos da comunidade foram estudar em San Ignácio.

Mesmo com uma resolução ministerial sancionada em 2012 (Resolución no 684 2012, Ministerio de Educación), a qual aprova que os currículos sejam regionalizados e válidos de acordo com idiomas oficiais do estado - o castelhano e os idiomas das nações e povos indígenas originários da região - no caso do povo indígena chiquitano, na língua bésiro. Os materiais didáticos utilizados na escola da comunidade de San Nicolas del Cerrito estão é na língua castelhana e em aimará, idioma da etnia do atual presidente. Assim Hall (2006) colabora:

A formação de uma cultura nacional contribui para criar padrões de alfabetização universais, generalizou uma única língua vernacular como o meio dominante de comunicação em toda a nação, criou uma cultura homogênea e manteve instituições culturais nacionais, como, por exemplo, um sistema educacional nacional.

Os professores declararam que há falta de materiais didáticos. Percebemos uma total falta de valoração da língua materna da comunidade, pois o currículo pode ser construído regionalmente. As pessoas que dominam esse conhecimento local poderiam atuar como docentes, acrescentando esses saberes ao que é transmitido e ensinado pela escola.

\section{A influência brasileira}

A fronteira na região é distinguida por marcos de concreto, cercas de arame sobre divisas secas e aquáticas (sobre a laguna Marfil). As bases militares de controle são insuficientes. A ligação com a cultura brasileira é muito forte na comunidade. A cidade de Vila Bela da Santíssima Trindade está mais próxima do que San Ignácio de Velasco, haja vista que a maioria dos homens trabalha e realiza compras no Brasil, em Vila Bela da Santíssima Trindade ou em Pontes e Lacerda. Alguns produtos brasileiros são comuns na comunidade: itens alimentícios, ritmos musicais e outros.

Os processos de aculturação são induzidos pelos padrões de homogeneização, o paradigma é o que se consome no Brasil e fazer compras no país vizinho agrega um status econômico e social, mesmo sendo mais caro do que realizar compras na Bolívia. Esse fato muda as práticas de consumo, os modelos tradicionais e o estilo de vida dos moradores da região. Ressaltamos que esse processo de relação entre os dois países não representa uma iniquidade. Vila Bela e San Ignácio de Velasco possuem enorme contingente recíproco de migrantes originários das duas cidades. Essa situação pode ser compreendida como integração cultural e 
social; porém, a aculturação por completo, as mudanças radicais de costumes e a massificação causam impactos e sérias consequências. Referindo-se à identidade, de acordo com Hall (2006):

Um tipo diferente de mudança estrutural está transformando as sociedades modernas no final do século XX. Isso está fragmentando as paisagens culturais de classe, gênero, sexualidade, etnia, raça e nacionalidade, que, no passado nos tinham fornecido sólidas localizações como indivíduos sociais. Estas transformações estão também mudando nossas identidades pessoais, abalando a ideia que temos de nós próprios como sujeitos integrados. Esta perda de um "sentido de si" estável é chamada, algumas vezes, de deslocamento ou decentração do sujeito. Esse duplo deslocamento - descentração dos indivíduos tanto de seu lugar no mundo social e cultural quanto de si mesmos - constitui uma "crise de identidade" para o indivíduo (2006).

As fazendas e suas práticas apresentam um novo modelo de relação com a natureza, sendo substituídas por novas com o objetivo de substituir alguns elementos já sacramentados (figura 08). Um fator preocupante é com a gradual troca dos conhecimentos étnicos culturais por conta dos novos subsídios inseridos devido à desconexão com a educação tradicional e com os ensinamentos culturais familiares. Um fator inquietante consiste nas práticas extrativistas, hoje restritas às pessoas com idades acima dos 50 anos.

Ainda com todas as novas configurações, a cultura é dinâmica. Mesmo ocorrendo muitas, essas pessoas não deixam de ser indígenas, tampouco são abandonados completamente os costumes tradicionais. Com o advento das gerações, a cultura apresenta-se com dinamismo. Há novas criações, recriações, novos elementos são inseridos (figura 08). Com a proximidade de fronteira, o modelo brasileiro de vida é muito comum na região, assim como as construções nas fazendas. Muitos objetos novos são introduzidos no cotidiano desse povo, outros são mantidos ou simplesmente substituídos.
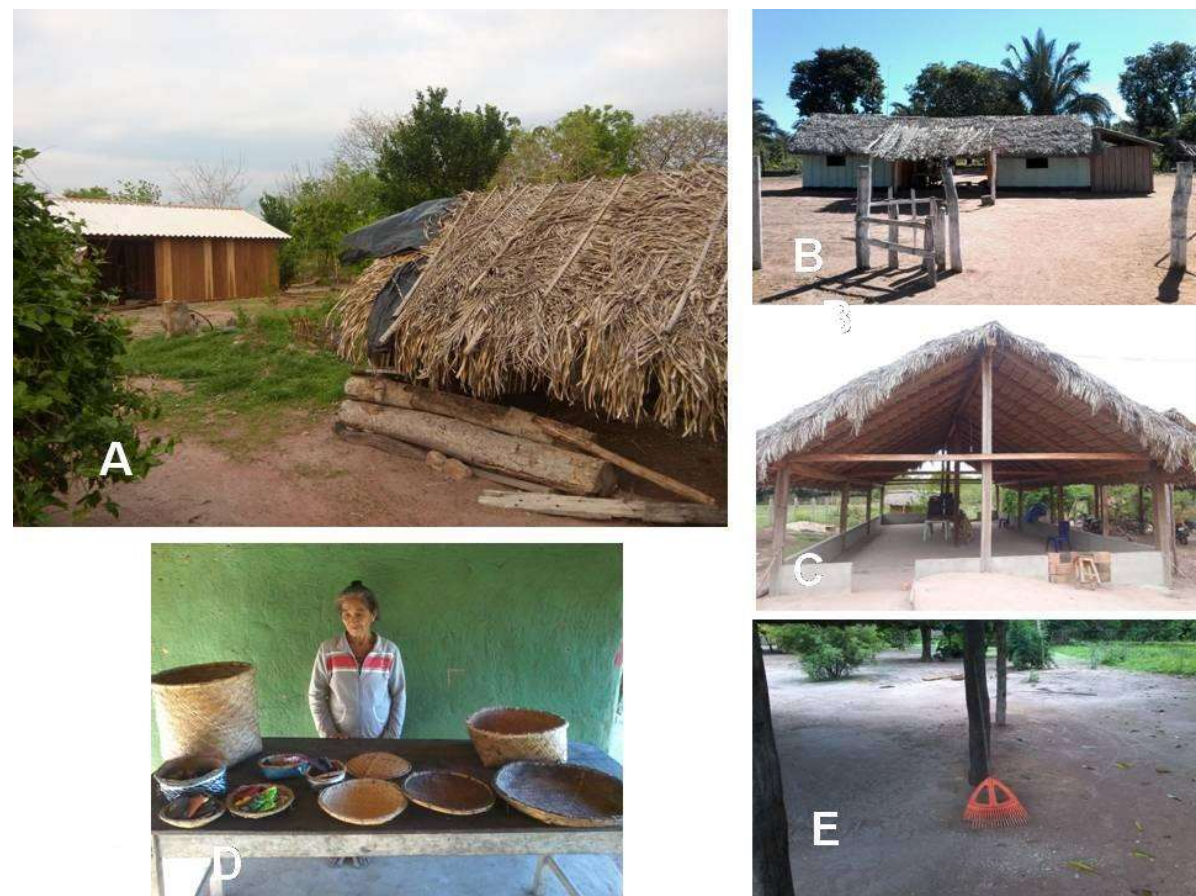

Figura 08 - Mudanças culturais. A) Substituição moradia tradicional por de madeira e eternit, B) Moradia coberta de palha feita de madeira, C) Espaço coberto palha, mas com armação de madeira serrada e concreto, D) Materiais pintados e alterados pela nova geração e E) Vassoura de plástico comprada cidade 


\section{CONCLUSÕES}

O estudo mostra aspectos históricos, geográficos, ambientais e culturais da comunidade San Nícolas de Cerrito que surgiu como alternativa para busca de liberdade e como modo de fuga de qualquer meio de opressão. Hoje a comunidade vive em meio ao domínio econômico da região, alicerçada na pecuária.

A comunidade San Nícolas de Cerrito é um espaço peculiar que ainda mantém costumes tradicionais autóctones na estrutura social, na arquitetura doméstica, nas materializações das roças, nos rituais de caça ou pesca, nas crenças espirituais com ligações ao bosque e aos cosmos. Como a cultura é dinâmica, as influências brasileiras são triviais na comunidade.

A entrada (cada vez maior) de imigrantes na região e a opressão do Estado por meio de normas e leis reforçam a preocupação da comunidade e das lideranças, que almejam "legalizar seus territórios e declarar seu usufruo" conforme as leis e obrigações estabelecidas.

Mesmo preservando algumas práticas tradicionais, com presença histórica no local, e contribuindo sutilmente ao criar suas configurações ecológicas peculiares, a comunidade hoje enfrenta desafios como interdição de seus acessos às fontes de recursos naturais, por políticas e normas do Estado boliviano.

Essa relação social entre Vila Bela e San Ignácio de Velasco é algo intrínseco à região e parte da identidade do local. As alterações culturais ocorrem naturalmente com o decorrer das gerações. Alguns fatores são simplesmente agregados à tradição ou são substituídos por completo. A realidade local ainda é determinante na manutenção das práticas culturais com, por exemplo, a energia elétrica, ainda inexistente, mantém o modus vivendi desse grupo. Caso seja instalada, poderá trazer profundas e rápidas alterações a esse povo.

A escola da comunidade tem papel fundamental na função de orientação dos moradores e valoração das práticas tradicionais, além de trabalhar pela manutenção da cultura local. Trata-se de um desafio enorme a ser administrado.

\section{REFERÊNCIAS}

ANTAS JR., R. M.. Território e regulação espaço geográfico, fonte material e não-formal do direito. São Paulo: Humanitas, 2005.

BARBOSA, A.. A experiência da imagem na etnografia. São Paulo: Terceiro Nome, 2016.

BERNARD, H. R.. Research Methods, in Antropology: Qualitative and Social Mechanism for buid Qualitative Approaches. New York: Altamira Press. 2006.

BIRK, G.. Dueños del bosque: manejo de los recursos naturales por indígenas chiquitanos de Bolivia. Trad. Alexandra Shand. Santa Cruz de la Sierra: APCOB, 2000.

COSTA, J. E. F. M.. A coroa do mundo: religião, território e territorialidade chiquitano. Cuiabá: Universidade Federal de Mato Grosso, 2006.

DESCOLA, P.. Estrutura ou sentimento: relação com o animal na Amazônia. Mana, v.4, n.1, p.23-45, 1998.
ERIKSON, P.. Animais demais... os xenibabos no espaço doméstico matis (Amazonas). Anuário Antropológico Revues, 2012.

GEERTZ, C.. A interpretação das culturas. Rio de Janeiro. Zahar, 1989.

GODOLPHIM, N.. A Fotografia como recurso narrativo: problemas sobre a apropriação da imagem enquanto mensagem antropológica. Horizontes Antropológicos, Porto Alegre, v.1, n.2, 1995.

IBGE. Instituto Brasileiro de Geografia e Estatística. Censo Demográfico 2010: Características gerais dos indígenas. Rio de Janeiro, 2010.

KOSSOY, B.. Fotografia e memória: reconstituição por meio da fotografia. In: SAMAIN, E.. O fotográfico. São Paulo: Hucitec, 1998. 
LÉVI-STRAUSS, C.. O pensamento selvagem. 12. ed. Campinas, SP: Papirus, 2012.

MALINOWSKI, B. K.. Argonautas do Pacífico Ocidental: um relato do empreendimento e da aventura dos nativos nos arquipélagos da Nova Guiné melanésia. 2 ed. São Paulo: Abril Cultural, 1978.

MAUSS, M.. Sociologia e antropologia. São Paulo: Cosac \& Naify, 2003.

NAVARRO, G.; Ferreira, O.. Classificacíon de la vegetacion de Bolívia. 2008. In: SALAZAR, R. S. M. Propuesta para la creación de la Reserva Municipal Laguna Marfil, Municipio de San Ignácio de Velasco. Santa Cruz, Junio de 2010.

NAVARRO, G.. Clasificación de la Vegatacion de Bolivia. Centro de Ecologia Difusión Simón I. Patiño. Santa CruzBolivia, 2011.

OLIVEIRA, R. C. D.. 0 trabalho do antropólogo. 2 ed. Brasília: Paralelo 15; São Paulo: Unesp, 2006.

ONU. Organização das Nações Unidas. Los pueblos indígenas de Bolívia: diagnóstico sociodemográfico a partir del censo de 2001. Santiago: ONU, 2005.

PUHL, J. I.. Converter índios "animais de Deus" em homens, cristãos e súditos civilizados. In: CASELLI, L. A.; MARTINS, M. C. B.. Histórias coloniais. São Leopoldo: UNISINOS; Cuiabá: EdUFMT; OIKOS, 2008.

PUHL, J. I.. Territorialidades chiquitanas em comunidades rurais da Província de Velasco, Bolívia, 1953-2006. Tese (Doutorado em História) - Universidade do Vale do Rio dos Sinos, São Leopoldo, 2011.

RIBEIRO, B. G.. Os índios das águas pretas: modo de produção e equipamentos produtivos. São Paulo: Companhia das Letras; EdUSP, 1995.
RIBEIRO, D.. Suma etnológica brasileira: etnobiologia. 3 ed. EdUFPA: Belém, 1997.

SANTOS, M.. A natureza do espaço: técnica, razão e emoção. 4 ed. São Paulo: EdUSP, 2006.

SALAZAR, R. S. M.. Propuesta para la creación de la Reserva Municipal Laguna Marfil, Municipio de San Ignácio de Velasco. Santa Cruz, Junio de 2010.

SILVA, G. J.. A Bolívia, a chiquitania e as populações indígenas em um mosaico étnico e cultural. Revista de Estudos e Pesquisas sobre as Américas, v.6, n.2, 2012.

SCHWARZ, A.. Yabaicurr - Yabaitucurr - Ciyabaiturrup: estrategias neocoloniais de "desarrollo" versus territorialidad chiquitana. La Paz: 1995.

SOUTO, F. J. B.. A imagem que fala: o uso da fotografia em trabalhos etnoecológicos. In: ALBUQUERQUE, U. P.; LUCENA, R. F. P.; CUNHA, L. V. F. C.. Métodos e técnicas na pesquisa etnobiológica e etnoecológica. Recife: NUPPEA, 2010.

TOLEDO, V. M.; AGUILLA, M. D. Las Plantas Utiles de Lomerio. Bolfor: Sabra Cruz, 1996.

TOLEDO, V. M. Povos: comunidades tradicionais e a biodiversidade. Instituto de Ecologia da Unam, Encyclopédia of Biodiversity Academic press. Mexico, 2001.

TONELLI J. O.. Riseña Histórica social y económica de la Chiquitania. Santa Cruz de la Sierra: Editorial El País, 2004.

TONELLI J. O.. Geografia, historia e naturaleza chiquitana. Santa Cruz de la Sierra: Imp. El país, 2011.

WHYTE, W. F.. Sociedade de esquina. Rio de Janeiro: Jorge Zahar Editor, 2005.

A CBPC - Companhia Brasileira de Produção Científica (CNPJ: 11.221.422/0001-03) detém os direitos materiais desta publicação. Os direitos referem-se à publicação do trabalho em qualquer parte do mundo, incluindo os direitos às renovaç̃ões, expansões e disseminações da contribuiç̃o, bem como outros direitos subsidiários. Todos os trabalhos publicados eletronicamente poderão posteriormente ser publicados em coletâneas impressas sob coordenação da Sustenere Publishing, da Companhia Brasileira de Produção Científica e seus parceiros autorizados. Os (as) autores (as) preservam os direitos autorais, mas não têm permissão para a publicação da contribuição em outro meio, impresso ou digital, em português ou em tradução. 